Supplementary Information

\title{
$\mathrm{ZnO}$ materials as effective anodes for the
}

\section{photoelectrochemical regeneration of}

\section{enzymatically active $\mathrm{NAD}^{+}$}

Carminna Ottone $^{a *}$, Diego Pugliese ${ }^{b}$, Marco Laurenti $^{b}$, Simelys Hernández ${ }^{b^{* *}}$,

Valentina Cauda ${ }^{b}$, Paula Grez ${ }^{c}$, Lorena Wilson ${ }^{a}$

${ }^{a}$ Escuela de Ingeniería Bioquímica, Pontificia Universidad Católica de Valparaíso, Av. Brasil 2085, 2340000, Valparaiso, Chile

${ }^{b}$ Department of Applied Science and Technology, Politecnico di Torino, C.so Duca degli Abruzzi 24, 10129, Turin, Italy.

${ }^{c}$ Instituto de Química, Pontificia Universidad Católica de Valparaíso, Av. Universidad 330, 2340000, Curauma, Chile

\section{Corresponding Authors}

*(carminna.ottone@pucv.cl)$) ; *(\underline{\text { simelys.hernandez@polito.it })}$ 


\section{ECSA calculation}

The electrochemical surface area (ECSA) was calculated as follows:

$$
E C S A=\frac{C d l_{i}}{C d l_{0} / G A_{0}}
$$

where $\mathrm{Cdl}_{\mathrm{i}}$ are the double-layer capacitances (in $\mu \mathrm{F}$ ) of the $\mathrm{ZnOW}, \mathrm{ZnOF}$ and $\mathrm{ZnOP}$ films and $\mathrm{Cdl}_{0}$ and $\mathrm{GA}_{0}$ are the double-layer capacitance (in $\left.\mu \mathrm{F}\right)$ and the geometrical area (in $\left.\mathrm{cm}^{2}\right)$ of the $\mathrm{ZnO}$ material used as reference.

The reference material used, $\mathrm{ZnOFlat,} \mathrm{was} \mathrm{a} \mathrm{smooth} \mathrm{film} \mathrm{of} \mathrm{ZnO}$. The latter was prepared by dip-coating an FTO substrate on a $10 \mathrm{mM} \mathrm{Zn}$ (acetate) solution prepared in ethanol. The substrate was left dried at room temperature and then calcined at $300{ }^{\circ} \mathrm{C}$ for $20 \mathrm{~min}$.

A cyclic voltammetry was performed in a region where any peak was observed. The current measured at $0.6 \mathrm{~V}$ with increasing scan rates in the range between 10 and $50 \mathrm{mV} \cdot \mathrm{s}^{-1}$ for all the $\mathrm{ZnO}$ materials is reported in Fig. $\mathrm{S} 1 . \mathrm{Cdl}_{\mathrm{i}}$ and $\mathrm{Cdl}_{0}$ are obtained from the slope of the graphs. Table S1 shows the physical data of the $\mathrm{ZnO}$-based electrodes.
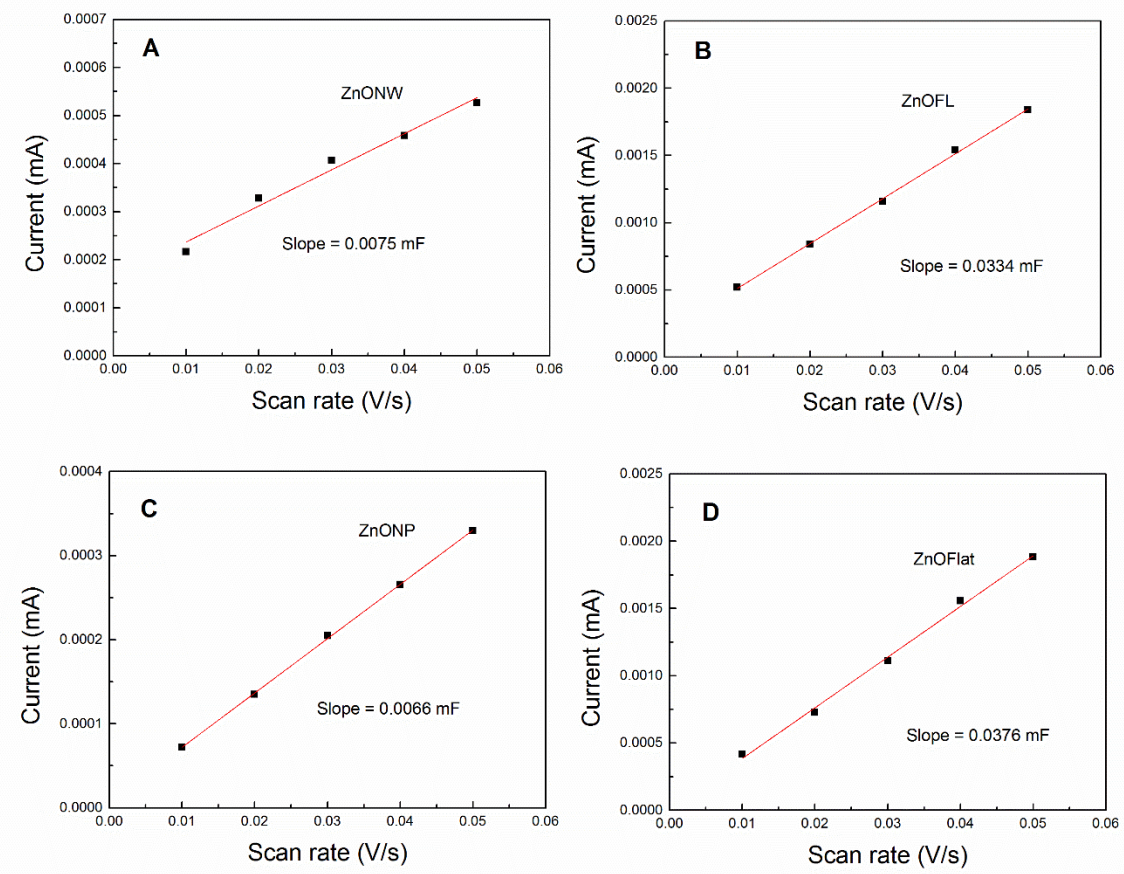

Fig. S1. Current measured at $0.6 \mathrm{~V}$ from the $\mathrm{CVs}$ at different scan rates for A) $\mathrm{ZnOW}$, B) $\mathrm{ZnOF}, \mathrm{C}) \mathrm{ZnOP}$ and d) $\mathrm{ZnOFlat.}$ 
Table S1. Physical data of the ZnO-based electrodes.

\begin{tabular}{|c|c|c|c|}
\hline Material & GA $\left(\mathbf{c m}^{2}\right)$ & Cdl $(\boldsymbol{\mu F})$ & ECSA $\left(\mathbf{c m}^{2}\right)$ \\
\hline ZnOW & 0.78 & 7.5 & 0.7978 \\
\hline ZnOF & 0.78 & 33.4 & 3.5531 \\
\hline ZnOP & 0.78 & 6.6 & 0.7021 \\
\hline ZnOFlat & 0.78 & 37.6 & N/A \\
\hline
\end{tabular}

N/A: not accessible

\section{Optical characterization}
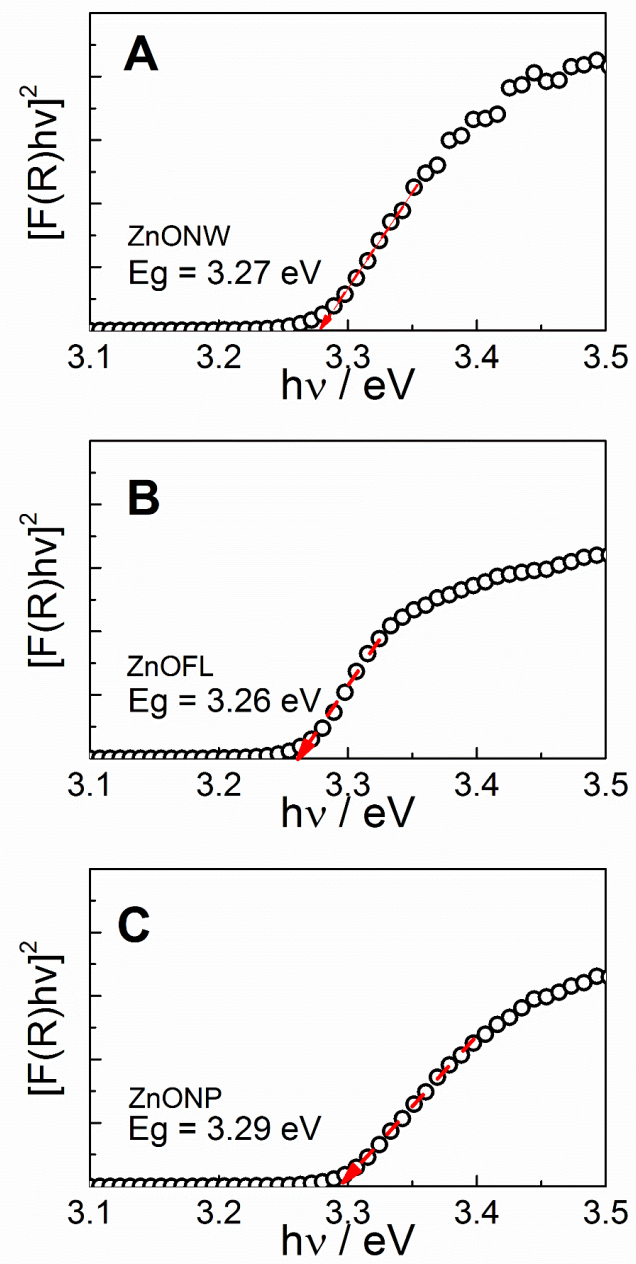

Fig. S2. UV-Vis spectra of A) $\mathrm{ZnOW}, \mathrm{B}) \mathrm{ZnOF}$ and C) $\mathrm{ZnOP}$. 


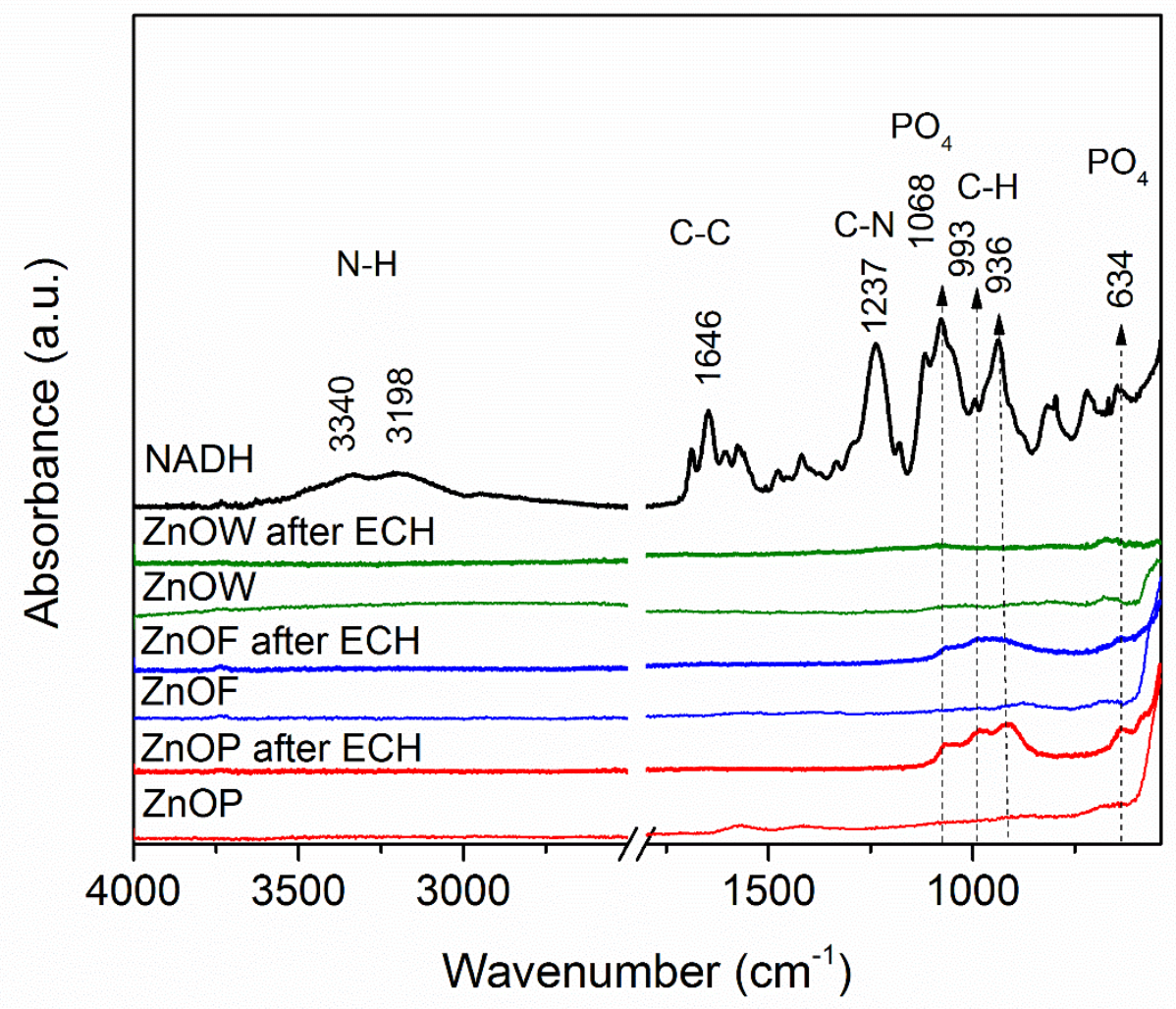

Fig. S3. Infrared spectra of the different $\mathrm{ZnO}$ films as-made and after the electrochemical tests. 